\title{
I do not know what else to do: caregivers' perspective on reassurance seeking in OCD
}

Article

Accepted Version

Creative Commons: Attribution-Noncommercial-No Derivative Works 4.0

Halldorsson, B., Salkovskis, P. M., Kobori, O. and Pagdin, R. (2016) I do not know what else to do: caregivers' perspective on reassurance seeking in OCD. Journal of ObsessiveCompulsive and Related Disorders, 8. pp. 21-30. ISSN 22113649 doi: https://doi.org/10.1016/j.jocrd.2015.11.003 Available at https://centaur.reading.ac.uk/70127/

It is advisable to refer to the publisher's version if you intend to cite from the work. See Guidance on citing.

To link to this article DOI: http://dx.doi.org/10.1016/j.jocrd.2015.11.003

Publisher: Elsevier

All outputs in CentAUR are protected by Intellectual Property Rights law, including copyright law. Copyright and IPR is retained by the creators or other copyright holders. Terms and conditions for use of this material are defined in the End User Agreement.

www.reading.ac.uk/centaur 
Central Archive at the University of Reading

Reading's research outputs online 
I Do Not Know What Else To Do: Caregivers' Perspective on Reassurance Seeking in OCD

Brynjar Halldorssona,,,1, Paul M. Salkovskisa, Osamu Koborib, and Rowena Pagdina

a Department of Psychology, University of Bath, UK

b Department of Psychology, Swansea University, UK

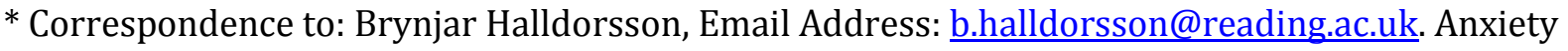

and Depression in Young People Research Unit, School of Psychology and Clinical Language Sciences, University of Reading, Early Gate, Reading, UK;

${ }^{1}$ Permanent address: Anxiety and Depression in Young People Research Unit, School of Psychology and Clinical Language Sciences, 


\begin{abstract}
Excessive Reassurance Seeking (ERS) is an under-researched and poorly understood behavior that resembles the compulsive behaviors that are typically seen in OCD. ERS can be complex, persistent, extensive, debilitating and may dominate people's interactions. In addition to resembling compulsive checking in OCD it may also have the effect of transferring responsibility to others. Caregivers are frequently asked to take part in a range of rituals as part of the OCD sufferer's problem, often seeing it as a way of supporting the sufferer. We are still in the early stages of understanding the factors that elicit and maintain these responses in caregivers. The present investigation considered the interpersonal components of ERS by applying an in-depth analysis using qualitative methods in the context of an interview of caregivers who provide reassurance to OCD sufferers. Ten interviews were conducted and analysed using thematic analysis. Seven overarching themes were identified as important in the experience of being asked for and providing reassurance. These concern factors such as how people seek reassurance, how they process it, why other people give it and so on. A particularly pervasive theme was caregivers' experience of frustration in the face of ERS. Clinical implications of the findings are discussed.
\end{abstract}

\title{
Keywords
}

Excessive reassurance seeking

Caregivers

Obsessive-compulsive disorder

Thematic analysis

Frustration

\section{Highlights}

- Excessive reassurance seeking is a complex interpersonal behavior

- Caregivers of OCD sufferers feel unable to cope day to day without giving reassurance

- Excessive reassurance seeking can lead to relationship problems and frustration 


\section{Introduction}

Excessive reassurance seeking is known to be particularly common in people experiencing OCD (Kobori \& Salkovskis, 2013; Kobori, Salkovskis, Read, Lounes, \& Wong, 2012; Kobori, Sawamiya, Iyo, \& Shimizu, 2014; Parrish \& Radomsky, 2010; Salkovskis, 1999) where it typically causes problems both for the sufferer and for those who are close to him/her and are trying to alleviate the suffering. The 'human cost' of excessive reassurance seeking is often high; clinical examples include individuals who frequently contact the police to check if there are any unsolved 'hit and runs', with the intention being to seek reassurance that they themselves did not commit a crime without remembering it and could not be accused of concealing it if they had. This can have disastrous results, such as being accused of wasting police time or even false confessions being accepted and leading to criminal conviction. A loving father not only avoids being close to his children but repeatedly asks his partner for proof that he has not sexually abused them. Although excessive reassurance seeking has previously received little research attention, our understanding of the function of this behavior has gradually improved in recent years. Several converging lines of evidence (Kobori \& Salkovskis, 2009, 2013; Kobori et al., 2012; Parrish \& Radomsky, 2006, 2010, 2011; Rachman, 2002) are consistent with the hypothesis that ERS can best be conceptualised as a safety-seeking behavior (Salkovskis, 1991), specifically a type of interpersonally focussed checking behavior. What makes ERS so 'special', in comparison to other safety-seeking behaviors, is that it not only serves to reduce perceived threat of harm but may also transfer perceived responsibility to another person (Kobori et al., 2012; Rachman, 2002; Salkovskis, 1996, 1999). The limited but growing literature on ERS consists mainly of studies where reassurance seeking is examined from the sufferer's perspective while the provision of reassurance remains poorly understood. Clinically we believe that caregivers (family members, friends, partners and so on) of OCD sufferers are often heavily involved in providing reassurance on the basis that they are an authoritative person who is 
familiar with the sufferer and their problems and may be able to provide a helpful 'external' perspective. Studies examining caregivers' involvement in OCD symptoms have mainly focused on symptom accommodation - an undifferentiated term generally used to refer to all behaviors or actions that caregivers engage in to prevent or alleviate the patient's obsessive compulsive symptoms. Within this literature, the provision of reassurance may be included simply as one example of symptom accommodation; however, there is evidence that ERS may be the most common manifestation of symptom accommodation across both adult and paediatric samples (Calvocoressi et al., 1995; Peris et al., 2008; Shafran, Ralph, \& Tallis, 1995; Storch et al., 2007). Clinical observation also suggests that, when caregivers accommodate, they are usually motivated by the desire to help the sufferer feel better in any way possible (Amir, Freshman, \& Foa, 2000). Also involved can be the effort to avoid potential conflicts, criticism, anger or even physical aggression by the sufferer (Albert et al., 2010; Lebowitz, Omer, \& Leckman, 2011). Symptom accommodation can also help to lower the caregiver's own levels of distress. Offering reassurance may allow some degree of normal everyday activity, such as the provision of reassurance making it possible for both the caregiver and the sufferer to leave the house with a minimum of checking time and later rumination. Although caregivers' involvement in OCD is most likely intended to reduce strain, particularly in the short-term, clinical experience suggests that relationship or family dysfunction almost inevitably develops as the OCD sufferer's needs for such help escalates. In the face of understanding that giving reassurance or carrying out rituals for the sufferer may be making things worse, caregivers often develop ambivalence and may begin to alternate between helping the sufferer with their rituals and directly opposing them. Research indicates that symptom accommodation is associated with higher levels of overall psychological and familial distress (Albert et al., 2010), higher levels of depression and anxiety in the relatives (Amir et al., 2000), poorer relationship functioning and treatment response (Boeding et al., 2013), greater OCD symptom severity (Stewart et al., 2008), refractoriness of OCD (Ferrão et 
al., 2006) and greater functional impairment for the OCD sufferer (Storch et al., 2010). As evidence for the importance of interpersonal variables in OCD emerges, so has research which seeks to improve interpersonal factors with the development of caregiver-based treatment interventions (Renshaw, Caska, Rodrigues, \& Blais, 2012). Although guidelines and manuals for treating OCD, particular for children (e.g., Bolton et al., 2011), advocate family involvement, with few exceptions (e.g., Abramowitz et al., 2013; Lewin et al., 2014; Renshaw, Steketee, \& Chambless, 2005) these family-based interventions tend to include a minor focus on the role of the caregiver in maintaining the problem and/or producing behavior change. The most common emphasis is on providing caregivers with psychoeducation about OCD and the process of exposure response prevention or incorporating them as coaches in exposure assignments (Mehta, 1990; Renshaw et al., 2012; Renshaw et al., 2005; Steketee \& Van Noppen, 2003). Although it is entirely appropriate and often necessary to involve family members in the treatment for OCD it is a matter of concern that the current family/caregiver based interventions are not empirically grounded in terms of how and why caregivers respond to OCD symptoms. In the treatment of excessive reassurance seeking, it seems that exposure response prevention principles still influence clinical practice (e.g., Abramowitz \& Braddock, 2008; Furer, Walker, \& Freeston, 2001; Rachman, 2002; Taylor, Asmundson, \& Coons, 2005). This usually takes the form of instructing the patient to stop seeking reassurance while asking family members to withhold reassurance or ignore such requests without regard to caregivers' understanding and experiences of ERS. Recent research evidence suggests that withholding reassurance can set off strong negative and behavioral responses in OCD sufferers and typically is known by sufferers and caregivers to result in increases in distress (Halldorsson and Salkovskis, in preparation; Salkovskis \& Kobori, 2015). What is needed is an empirically grounded and more focussed intervention. Cognitive Behavioral Treatment (CBT) that focuses on treating ERS by helping the sufferer to shift from seeking reassurance to seeking support (a non-pathological interpersonal behavior) is a 
particularly promising development (Halldorsson \& Salkovskis, in preparation). For example, telling a trusted person how bad you feel and how difficult it is not too give in to the compulsion and in that context asking for encouragement to overcome the urge to compulsively check, as opposed to asking for repeated reassurance that the feared catastrophe is not going to happen.

\section{Study Aims}

The main aim of the present investigation is to help to fill the gap in understanding of the reactions of caregivers to reassurance seeking by specifically gathering information about their experiences and understanding of reassurance seeking within the context of OCD. The intention is to gain more in-depth understanding of why caregivers constantly give reassurance, what reasons influence their decisions to give or withhold reassurance, what they consider the effects of giving/withholding reassurance to be, and their experience of the interpersonal effects of persistent reassurance seeking.

\section{Method}

\section{Design}

The protocol of the current study was approved by a NHS Research Committee (Ref. 07/Q0706/39). Caregivers of OCD patients completed a semi-structured interview that was specifically developed for this study and aimed at gathering information about participant's understanding and experiences of reassurance seeking within the context of OCD. Theoretical thematic analysis (Braun \& Clarke, 2006) was performed on the interview transcripts and relevant themes identified.

\section{Participants}

Ten carers volunteered to participate in the study, recruited through a specialist OCD treatment unit $(n=5)$ where the person suffering from OCD was having treatment, and from OCD charities in the United Kingdom ( $n=5)$. Participants were required to identify themselves as a partner or a family member, acting as a main caregiver for an adult OCD sufferer who frequently sought reassurance from them. Participants were consecutively included in the 
study on the basis of their partner's clinical diagnosis of OCD and on their descriptions (and investigators' observations) of the severity and negative interpersonal impact caused by the OCD sufferer's persistent reassurance seeking. Fourteen participants completed the screening process. Two participants were excluded based on the OCD sufferer's comorbid diagnosis of autism spectrum disorder and two participants dropped out when the details of the study were explained and consent sought.

\section{Materials}

A semi-structured interview schedule was specifically developed for this study. The interview schedule can be obtained on request from the lead author.

\section{Procedure}

All interviews started with a brief summary of the stated study aims: to discuss their experiences and understanding of reassurance seeking within the context of OCD, and given the opportunity to ask questions regarding any aspects of the study. The interviewer had no contact with the OCD sufferers who were not present at the interview. In terms of the interview structure, the interviewer encouraged participants to elaborate on their answers, avoid simple 'yes' and 'no' answers and instead try to give as much information as possible. The interviewer was also allowed to prompt participants if he considered the answer not to be complete and participants were encouraged to seek clarification if they felt unsure about particular questions. On average the duration of the interviews was approximately 30 minutes. Each interview was recorded using a digital recording device and then transcribed verbatim by an independent transcriber. Each participant received a $£ 10$ voucher as a token of thanks for their participation.

\section{Data Analytic Strategy}

The current data set comprised 10 transcribed interviews, which were analysed in accordance with the established guidelines of thematic analysis, which offers an accessible and theoretically flexible approach to analysing qualitative data (Braun \& Clarke, 2006). The 
analysis was conducted by the interviewer $(\mathrm{BH})$ who is a clinical psychologist and experienced in treating emotional problems including OCD. Thematic analysis as described by Braun and Clarke (2006) involves various steps aimed at extracting themes from the data. In summary, these steps involve: familiarizing with the data, generating codes and collating the data, extracting themes from the coded data, reviewing and refining the extracted themes, defining and naming themes.

\section{Results}

\section{Demographic Information}

The participants consisted of nine women and one man. The average age was 44.33 years $(\mathrm{SD}=17.85)$. Seven individuals reported being the sufferer's partner, two were the sufferer's mother and one participant was the sufferer's daughter. At the time of interviewing 9 out of 10 participants shared their home with the OCD sufferer and the duration of the caring role ranged from 8 to 30 years. The OCD sufferers consisted of five males and five females. They had been suffering from OCD for 8 to 35 years.

\section{Overview of the Thematic Analysis}

Six overarching themes, eighteen subthemes and one superordinate theme emerged from the thematic analysis. In the following section each theme is described in detail. All overarching themes (and the superordinate theme) are written in bold and capital letters. Subthemes are written in italic and underlined. All themes are presented visually in a thematic map shown in Figure 1.

\section{REASSURANCE UNDERSTOOD AS A REACTION TO THE PERCEPTION OF THREAT}

This overarching theme represents caregivers' experience and views of reassurance seeking. It taps into the different aspects of the behaviors, such as the forms ERS can take (direct or indirect), and what seems to drive and trigger reassurance seeking from the caregivers' perspective. Overall this theme reflects the phenomenology of the behavior. Caregivers felt that reassurance is sought about perceived threats of harm resulting from doubts or making mistakes (e.g., "did I turn everything off?"), contamination related worries (e.g., "is this safe to 
eat?") and/or causing harm (e.g., "am I dangerous?"). Caregivers reported that requests for reassurance typically involved direct verbal questions (e.g. "did you see me check?") or nonverbal interactions such as 'happy-looking' facial expressions. In all instances the caregiver knew they were meant to communicate reassurance by indicating (sometimes repeatedly) that things were/will be 'ok', and/or clarifying or (dis) confirming threat related topics. Overall participants felt that reassurance was employed by the OCD sufferer to reduce negative feelings, in particular anxiety. Most participants (eight out of ten) felt that reassurance was unhelpful and had a negative impact on the long term course of OCD. Interestingly, three participants specifically reported that reassurance seeking was helpful interaction to deal with distress or feelings of anxiety in 'normal people', but not for people with OCD where it appeared to them to function differently, become unhelpful and maintain the anxiety problem. Finally, the analysis supports previous research that reassurance seeking can take different forms, such as not including other people directly (i.e. selfreassurance, or is sought in hidden ways where people may provide reassurance without realizing it).

Saying things will be 'ok', clarifying or confirming: Early on in the interview participants were asked to explain what they felt reassurance seeking was (i.e. how they defined and understood it). Overall, participants described reassurance as a verbal or non-verbal interaction that coincided with heightened feelings of anxiety. Some participants understood reassurance as a way of telling the OCD sufferer that 'things are going to be ok': "Reassurance is where I constantly say to him that everything's going to be ok...” (Participant 4); “... it's reassurance that she, that things are OK, that you know, not to think about things too much, just kind of explain that things are OK really" (Participant 3). Other participants defined reassurance as giving clarification or confirming the accuracy or completion of certain tasks: "I would say it's giving somebody clarification on something they're concerned about. It's kind of 


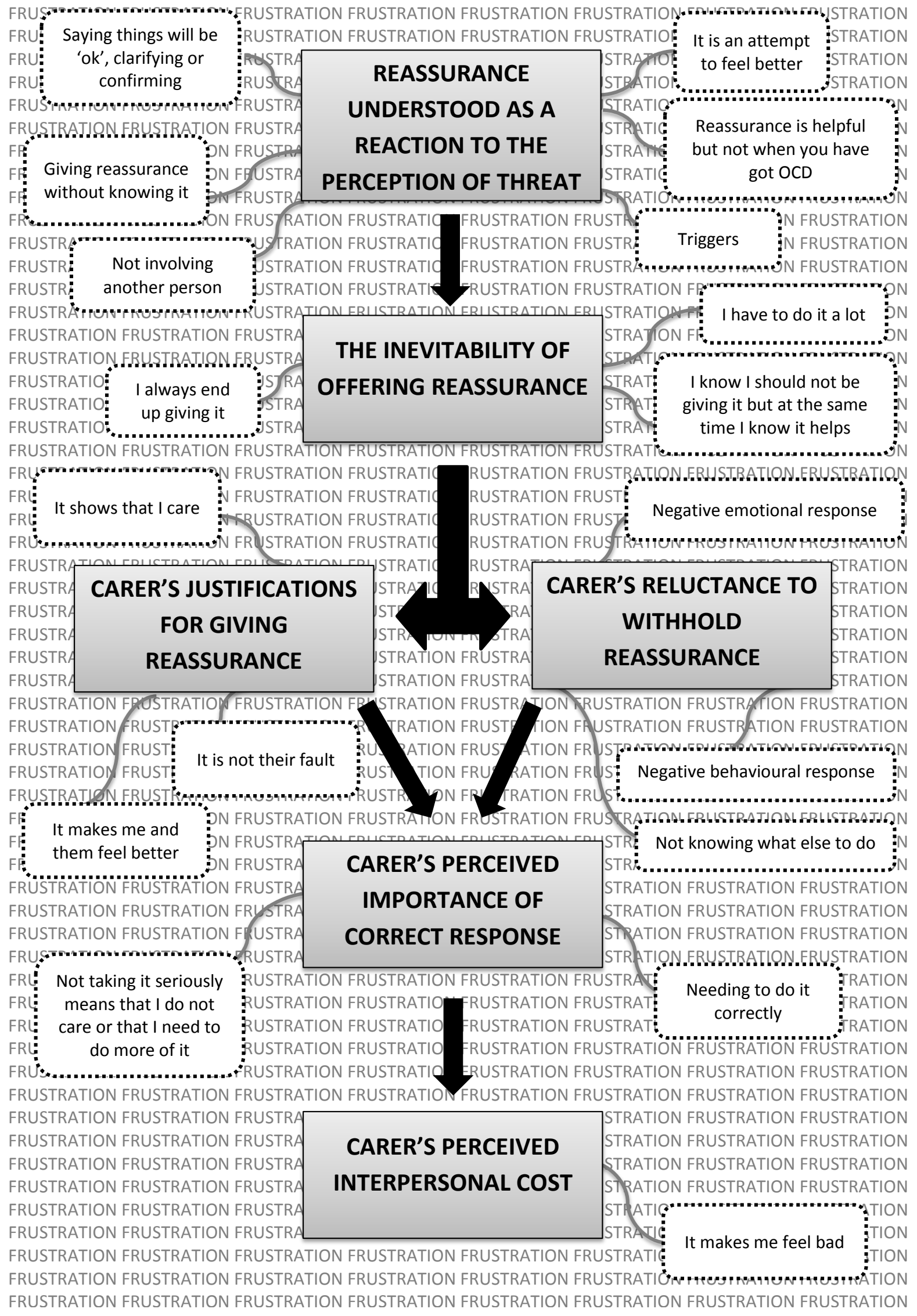

Figure 1. Thematic map of caregivers' understanding and experiences of excessive reassurance seeking. Overarching themes are represented in grey coloured boxes. Lines link each subtheme to its overarching theme. The superordinate theme 'Frustration' is shown in grey capital letters to reflect how this superordinate theme cut across most overarching themes. 
affirming what they think so, if somebody asked you if they did something, then saying, "Yes you did do that, that did happen" and making them feel better (Participant 7); "Generally it's about asking if things are off, like the oven. So I might be asked "Is this switched off?" or "I'm worried that this isn't straight, that the, that the switch isn't straight when it's meant to be so maybe it's still on..." and would I check in order to reassure her that it is off... that sort of thing"(Participant 5). Other participants mentioned that in their experience reassurance seeking involved responding to the meaning of obsessive thoughts ("no I don't think that because you had this thought you are in any risk of stabbing our children"), or offering information about feared contaminants ("yes...your hands are clean").

It is an attempt to feel better: The perceived motivation for seeking reassurance is clearly an important issue, in terms of explaining why and how people respond to requests for reassurance. When asked to reflect on the sufferer's motivation/s for seeking reassurance, all participants reported that reassurance seeking coincided with high levels of anxiety or worry. In their mind the primary motivation for seeking reassurance was to counteract those negative feelings, in particular anxiety, by reducing the perceived danger or threat. For example, Participant 5 reported when she was asked why she thought her partner sought reassurance: "To reduce her anxiety around whatever it is that she's worried about."; Similarly, Participant 9 said: "Because he's worried and distressed, and he needs to, something that I say will provide reassurance and that will lessen the anxiety." Two participants specifically mentioned other motivational factors such as 'the dispersion of responsibility' or 'intolerance or uncertainty' as a potential motivation for seeking reassurance. As an example Participant 6 commented: “... it shares the responsibility. So for example, you know, the checking won't, the physical checking she would like me, she doesn't always ask me, but she would like me, really I think, to go around the house and check the things she wants to check. Because once again the responsibility is shared, you know, if we come out the house and we find that the lights had been left on, well I checked as well so it can't just be her fault." 
Triggers: As expected, all ten participants were frequently requested, by the OCD sufferer, to give reassurance. They reported that reassurance was usually sought from them (triggered) after the sufferer had experienced intrusive and unpleasant involuntary thoughts (e.g. harm coming to someone), doubts (e.g., "are you sure I locked the door?") and/or anxious mood or a mixture of all three. This was evident in all interviews. When asked what they felt triggered reassurance seeking in their loved one, Participant 4 said: "Its normally when he's very anxious and he's worrying about something and the OCD has kicked in, the thoughts are really bad and then he'll ask me, at his worst, he'll ask me a lot of times a day." Similarly, Participant 1 said: "If my boyfriend is doubting something or if he has a thought that he can't get rid of, he'll ask me for reassurance."

Reassurance is helpful but not when you have got OCD: Participants were asked to reflect on their views of reassurance seeking, more specifically whether they felt reassurance within the context of OCD was 'good' or 'bad'. Eight participants out of ten reported that reassurance was unhelpful and had a negative impact on the long-term course of OCD as an anxiety problem. This is particularly interesting given that the same participants reported elsewhere (and consistently) during the interview that their typical reaction to a request for reassurance was to provide the reassurance. Participant 2 said: "In the long run I know it's bad because it simply feeds the OCD and it makes it worse"; Similarly, Participant 5 said:" Generally I think it's bad because it tends to just continue the cycle, and provides reassurance for a very short period of time. I think with the nature of OCD it doesn't really stick because that's the whole point of it." What stood out was that three participants specifically reported during the interview that reassurance seeking was generally helpful in terms of dealing with negative feelings, but not if people had OCD, where it appeared to them to become counterproductive. This was for example highlighted by Participant 6 who commented: “Well, in general I suppose it's seen as a positive thing, you know, to reassure someone sounds like a nurturing caring word. So I think it's probably seen in general as a positive thing. In my 
experience, from reassuring my mum from an OCD point of view, in the short-term it's kind of, I think it lowers her anxiety to an extent, but in the long-term I don't think it is helpful, just because it doesn't sort of solve anything, it just provokes more questions and more reassuranceseeking behavior really."

Giving reassurance without knowing it: Reassurance seeking can be very subtle, in some cases even hidden, where reassurance appears to be somehow communicated without the provider's knowledge. Participants were asked about their experiences of subtle reassurance seeking or if they had experienced giving reassurance without realizing it until later. Of the ten participants, six had experienced this to some degree. Participant 7, for example, said: “...I guess the one thing he does do is creep off to bed without telling me, so I'll have to lock up and turn the lights out kind of thing, so I guess that's him being a bit tricky in a way then because he knows it's a way of for him, I would class that as reassurance in itself, that I'm doing it rather than him. So not just verbal reassurance, but he's confident in me doing it but he's not confident in him doing it, so it's a kind of form of reassurance in that I'm doing it for him." Another participant mentioned how her daughter would sometimes not ask verbally for reassurance but found certain facial expressions reassuring for example when eating foods that she feared might be contaminated: “... casting glances is one...” Interviewer: "So she would look at you in a specific way?" Participant 2: "Yeah, if she's eating all she has to do is look at me and then I kind of nod and then she'll take another bite and then she'll look again."

Not involving another person: Eight participants out of ten reported having noticed the OCD sufferer trying to reassure himself/herself when feeling anxious. In most cases the examples given involved the OCD sufferer mentally reviewing checks or talking out loud while engaging in checking rituals, or looking for information on the Internet. As expected 'self-reassurance' excludes any direct interpersonal contact, authority or reaction from other people. Participant 7 said: “...part of his checking and rituals are telling himself he's done something. I'll 
over-hear him and he'll be looking at a lamp that's off going "That's off, I've turned the lamp off, that's off" so he's telling himself that as if... if he verbally says it out loud it means it's true."

\section{THE INEVITABILITY OF OFFERING REASSURANCE}

This overarching theme describes how frequently (and persistently) caregivers are requested to give reassurance and how they typically respond when confronted with such a request. All participants reported that their typical reaction was to provide reassurance - in fact, they reported finding it inevitable. This is particularly interesting because most caregivers also described strong negative beliefs about giving reassurance to someone who suffers from OCD. At best it was a 'temporary fix'. Furthermore, the analysis suggests that caregivers are typically asked to provide reassurance repeatedly, once is not enough. Sadly, some relationships appear to be completely consumed by reassurance seeking and giving. I have to do it a lot: Participants were asked how frequently reassurance was sought from them. Eight out of ten participants said that they could not put a number on it; they simply felt that they were repeatedly asked for reassurance. “...on a bad day it would be almost, you know, one after the other after the other. And I kind of lose count" (Participant 6). Participant 8 and Participant 2, both described examples of how this behavior can become so excessive that it completely dominates people's lives: “... to me it feels constant. He'll say, “That's dodgy isn't it?" and I'll say, and I will try and say no it's not, he's got better in that respect, but I'm still having to reassure him all the time. I'm not always agreeing that it's there, but I'm saying no it's not there, and he has to try and say back to me that it's just my mind telling me it's there (Participant 8); “Practically constantly, I mean all the time with eating and drinking, all the time. Everything and going into the shower and getting dressed" (Participant 2).

Ialways end up giving it: When asked about their typical response to requests for reassurance, all participants reported giving reassurance when asked to do so although there was some variability in terms of how quickly they gave into the requests. Six participants out of ten reported that they tried to avoid giving it by providing something different such as 
reminding the OCD sufferer that reassurance seeking fuelled their OCD and should thus not be sought and/or given. In other instances caregivers appeared to be trying to de-flect or defocus the attention away from the perceived threat. Although done with best intentions, these attempts usually did not have the desired effect (i.e. the caregiver ended up giving reassurance): “Well as I've said, yeah, I tend to give it. I will try and explain again and again, and I keep on explaining the same things that really that we know that it's best that I've heard that it's best just to let the thought stay there and try to ignore it and not react on it and I'll try and be reasonable and I've thought of similes, like 'oh you know how trees are blown down in a storm but reeds just bend in the wind, and when the storm comes you've got to be a reed' and I'll try and go through all that sort of stuff. And obviously I'm giving reassurance in the end, and she says "It's not my fault" well no, of course it's not your fault" (Participant 2).

I know I should not be giving it but at the same time I know it helps: As mentioned above eight participants out of ten felt that reassurance was unhelpful and potentially damaging for the long-term development of OCD. However, the same participants still felt incapable of withholding reassurance. Participant 2 summarized this predicament when she said: "In the long run I know it's bad because it simply feeds the OCD and it makes it worse, I know that, but in the short-term when she's distressed or stressed and when it's a matter of getting her, in her case, to eat or drink or wash or whatever then it seems a reasonable thing to do." Similarly, Participant 7 said: "I would say that it has an immediate kind of good effect on the person with the OCD, it's good for them because it makes them stop worrying or at least lessens the worry but I find it frustrating because it's I guess unnecessary in that we both know the answer is "Yes the door is locked" for example." Later in the interview participants were specifically asked if they thought reassurance only worked temporarily. Nine participants felt that way (keeping in mind that they all typically gave reassurance), that is, in their experience the doubts or fears driving the OCD swiftly returned after reassurance was provided and the decrease in negative feelings was temporary at best: “It's good for a very small amount of time, ten 
minutes, and then after that he will ask me again so the reassurance only lasts for a very short time" (Participant 4).

\section{CAREGIVER'S JUSTIFICATIONS FOR GIVING REASSURANCE}

This overarching theme represents the caregiver's motivation/s for providing reassurance. That is, what reasons direct their decision/s to give (as opposed to withhold) reassurance. Three key factors were identified. Firstly, participants described how giving reassurance sometimes had a twofold effect, where on one hand it helped to make the sufferer feel less anxious and on the other hand gave themselves the chance to focus on something different and/or continue with what they wanted to do (as opposed to withholding reassurance and causing more persistent reassurance seeking). Another important motivational factor that was identified had to do with showing care and/or love for the sufferer where giving reassurance appeared to communicate those feelings. Finally, some caregivers talked about reassurance seeking being part of OCD, meaning it was not under the control of the sufferer. Thus, they should provide reassurance when request to do so.

It makes me and them feel better: Six participants out of ten said that they gave reassurance to make the sufferer feel better by alleviating negative feelings, such as anxiety or stress: "To make him feel better. It seems like an automatic response, someone asks you a question and you just answer. You don't think not to, and also to make him feel less stressed." (Participant 7); “To reduce anxiety for a small period of time” (Participant 5). Three participants reported that giving reassurance could potentially decrease their own levels of distress and/or make their life easier. For example, Participant 6 said: “I do it because I know my mum says it's helpful, and in the short-term it sort of, it's easier for me in a sense because I know that if I don't she'd get distressed and it would, it would make things worse really."

It shows that I care: Five participants said that they provided reassurance because of 'love' or 'care' for the person suffering from OCD as the following example suggests: "Because she's my daughter and I can't bear to see her suffering and I don't know what else to do until we get 
again expert help, you know what that's like. It's all I can do, and I know, as I said in the thing (earlier) I know it's not the way to go, I realise this very clearly, but I just don't know what to do" (Participant 2).

It is not their fault: In four interviews participants said that the OCD sufferer was not to blame for persistently seeking reassurance because the behavior was part of OCD and thus not under the sufferer's control. Consequently they felt that giving reassurance was an integral part of their role as a caregiver and a way for them to show support: "X has had this 17 years now so when he first had this, I really didn't understand anything about it and I just thought 'oh we've just had a baby girl' and I just thought it was the shock of being a father, and so my react to start with was you know 'come on, pull yourself together, there's nothing wrong' but as time has gone on I understand it a lot more now and I know that he can't help it. It's one of those things that he's got and we have to learn to manage it." Interviewer: "So you typically react with providing reassurance?" Participant 4: "Yes, I'm very straight forward now."

\section{CAREGIVER'S RELUCTANCE TO WITHHOLD REASSURANCE}

As part of the interview, participants were asked to describe how the person suffering from OCD reacts and feels when (or if) reassurance was withheld from them, that is, if the caregiver simply refused to give or ignored any requests for reassurance. This overarching theme is meant to reflect participants' reluctance or hesitation to withhold reassurance. Participants described how not responding accordingly to requests for reassurance could trigger a negative emotional response, particularly increased anxiety in the OCD sufferer. They also described negative behavioral responses, where withholding reassurance led to confrontations and for some meant that the sufferer's basic functioning, in terms of eating food and drinking water, was adversely impacted. Participants also reported that the decision making process is further complicated by the fact that they feel they cannot utilize other strategies when reassurance is sought from them. In other words, they often find that giving reassurance is their only option. 
Negative Emotional Response: Seven participants said that withholding reassurance would cause a negative emotional response typically in the form of increased anxiety (mentioned by five out of ten participants): "She gets a lot more anxious. I have tried, because I, I've tried different ways of dealing with it myself, and I did try and sort of saying OK I'm not going to talk about this, we know that this an OCD type worry and I'm not going to engage in talking about it. And that really heightened her anxiety and made her quite distressed, and it didn't seem to help and so yeah, I think certainly, sort of not listening to her worry seemed to be worse, makes her more anxious" (Participant 6). One participant mentioned his partner becoming very frustrated when reassurance was withheld which could result in him using alcohol as a way of tackling his anxiety: “He can get very frustrated... I mean he’s not aggressive as in he would never touch me or anything but you can see he is frustrated. Sometimes he can turn to alcohol so he'll drink to try and suppress the frustration or anxiety, but he never... he wouldn't do anything, he wouldn't sort of lash out or anything" (Participant 1). Another participant felt that withholding reassurance triggered feelings of hurt or upset: "Well I think there certainly are situations where he's mentioned things and I haven't said something reassuring. Oh, I don't know, you don't always feel like it. And he's upset, because I'm not backing him up or because he feels I don't understand, or because he's upset about a situation to begin with and having someone reinforce to him that that was the wrong thing to do or say, or that it's too upsetting and distressing and he feels hurt and upset" (Participant 9).

Negative Behavioral Response: Five participants said that withholding reassurance triggered a negative behavioral response in the sufferer. For example, Participant 2 described how failing to reassure her daughter, who was experiencing severe contamination fears, would impact on her basic functioning: “...If I don’t [give reassurance] she will not eat, she will not drink, she will not get up out of bed, she will not dress, she will not wash". Similarly, Participant 3 said: "I think, you know, quickly it would spiral to something that could get quite out of control. She just wouldn't be able to function properly, wouldn't be able to think and do things properly. I 
could see it getting really quite out of control." Another participant (Participant 8) described how withholding reassurance from her partner, who had fears about accidentally harming other people, led to confrontations: "... if it's quite a severe thing I think he could flip, you know it could be cause of, I don't know, he's got cross for. You know, if I've almost refused to do something he says Oh I'm never going to go in the car again. And some things he's threatened with are just not feasible. And it's just not worth doing, it's just worth saying, yeah it doesn't exist. For me it's just that."

Not knowing what else to do: During the interview, participants were specifically asked to share their ideas or views on how to cope without giving reassurance. Overall they reported not being aware of any other effective solutions/strategies and more than half of the participants reported what could best be described as feeling completely helpless against persistent reassurance seeking. Interviewer: "Do you have any ideas to cope without giving reassurance?" Participant 10: "I am too frightened of even trying to." As reported earlier in the interview, some participants reported having tried various different 'tactics' or 'strategies' with mixed results: “... I have tried, I sort of read books on it myself when she was displaying the symptoms of OCD, and I did try, like, either not talking about it, not entering into the discussion, which made her very anxious and didn't seem to work at all. And also repeating a certain phrase so that, you know saying, "you know that won't happen", and every time she asks the question I would say the same answer. But again that was just really anxiety provoking for her. So there were kind of things that I tried myself, but no, I don't really know other ways to deal with" (Participant 6). Four participants out of ten said they had tried to use deflection or de-focusing. For some that appeared to help occasionally: “... [I] redirect her to use strategies that she has already learnt through therapy and guidelines to do at home to manage her OCD, so for me it's about redirecting" (Participant 5). But for others that seemed to make matters worse: “... sometimes I wouldn't answer him or I would deflect or do something, but that makes him more anxious and I don't want to see him more anxious" (Participant 1). 


\section{CAREGIVER'S PERCEIVED IMPORTANCE OF CORRECT RESPONSE}

This overarching theme represents the process that occurs when the OCD sufferer is responding to the reassurance (and processing it or doing something with it). As part of the semi-structured interview participants were asked how long it takes until they stop giving reassurance and also to reflect on how closely they felt they were listened to (monitored) when communicating the reassurance (either verbally or non-verbally). They were also asked to discuss the consequences of not thinking seriously or looking casual when responding to requests for reassurance. The analysis highlights interesting differences in some of the features (criteria) involved in reassurance, or more specifically how OCD patients can differ in what they find important or necessary for reassurance to be helpful, trustworthy or convincing. Some OCD sufferers appear to place strong significance on the 'correctness' of the response they get where, for example, certain facial expressions must be either present or absent for reassurance to have the desired effect. Equally, 'just right feelings' appear to play a role as well, since some participants described having to give reassurance until negative feelings experienced by the OCD sufferer had dissipated. Consequently, some caregivers described the process being very time consuming, spending up to 20 minutes offering reassurance or even few hours a day in the more severe cases. Some participants also described the significance their loved one placed on them being extremely attentive and taking all requests for reassurance very seriously. Failing that typically resulted in more persistent reassurance seeking or meant that the caregiver was unsympathetic towards the sufferer.

Needing to do it correctly: Three participants reported that they had to give reassurance in the 'correct' way for it to work. This could for example include the absence or presence of certain facial expressions (e.g. happy looking face) while reassurance was communicated. The same participants felt that they were being listened to very carefully during the process and had been criticized if their reassurance was not considered good enough. These results 
highlight the various components involved in reassurance, that is, it is not just about what people are saying but also about how they are saying it. The following participant describes this very clearly: “...I have to look her directly in the eyes, not be distracted, and have a happy smiling face, and the second time or the third time that she asks it, she comes right close up so she's looking right into my eyes and if she happens to be in a particularly stressed mood for some reason, there have been occasions where she's asked me not to blink. She has to have the reassurance without me blinking at all." Interviewer: "And does she ever question the content or quality of your reassurance?" Participant 10: "No because I do it correctly."

Not taking it seriously means that I do not care or that I need to do more of it: Three participants said that if they looked casual or appeared to be not taking the request for reassurance seriously it carried the suggestion that they did not care for the OCD sufferer: “...it would make him feel very much as though I didn't care. It comes across as though 'Oh god, here we go again.' With your facial expressions you cannot do that. You have to make them feel safe" (Participant 4). Others said that when they expressed dis-interest it meant that further reassurance was sought: "She would continue until I did it correctly" (Participant 10).

\section{CAREGIVER'S PERCEIVED INTERPERSONAL COST}

This overarching theme reflects the negative emotional reaction that is elicited in participants when reassurance is sought from them. For example, they reported that persistent reassurance seeking had a negative impact on their relationship with that person and feelings of anger, disappointment, upset and particularly frustration were common. These negative emotional reactions appear to be related to the participants' experiences and beliefs about the counter-productive effects of providing reassurance and also their limited access to other (potentially more helpful) approaches/reactions to deal with persistent reassurance seeking.

It makes me feel bad: Eight participants out of ten identified experiencing feelings of anger, frustration, upset and disappointment as a result of being constantly asked for reassurance: 
"I feel] more upset than angry. Also frustrated, you know, I want him to stop asking me. And more for him, you know, I can't say stop thinking about it. I sometimes say can't you think about something else? Don't you have anything else to think about? You know. I know he can't control it, well he can control it to some degree, but it's almost like, why can't he think about other things? If he's thinking about that so much why can't he start thinking about other things, as in good things? So it's more frustration. But angry and upset... yeah on stuff that I can't change and I don't know how that we can move forward on it unless he confronts it" (Participant 8). Further negative emotions were also expressed by the participants. In five cases, feelings of guilt appeared to be triggered either after they had expressed their anger or frustration, or because they felt that by giving reassurance they were making false promises: "I $d o$ sometimes get angry and I feel terrible afterwards... But because I know my mum's an intelligent woman, I find it very frustrating that she's asking me this ridiculous question, so yeah, I do get quite angry. But then it upsets me to see her upset by it, it's a bit of both really" (Participant 6); "I felt guilty and worried because I know that I can't promise that X won't die..." (Participant 10).

\section{FRUSTRATION}

One particularly interesting observation made while reading through all the interview transcripts often in multiple places was how frequently the participants reported feeling frustrated as a result of being persistently asked to provide reassurance. In fact this 'superordinate' theme cut across most of the other overarching themes: "I get frustrated, at my most patient I'll be ok, I mean I can completely understand where it's coming from but then if I'm feeling a bit less patient then I can be frustrated and annoyed, mostly because I know she knows what's going on, so that is particularly frustrating and then also knowing that it doesn't really help, and it doesn't help in the long-term management of OCD. That's why I find it frustrating. Mostly because I know she knows, that's the most frustrating thing" (Participant 5). The caregivers also felt that the same emotion (i.e. frustration) was 
commonly experienced by the OCD sufferers as the following examples suggest: "...he looks a bit frustrated because he knows he's asking something to do with his OCD and I know it's to do with his OCD, and he looks a bit kind of embarrassed that he's kind of opening up and being like that with me. I think he'd rather try and hide it but I think it comes out in that way" (Participant 7); She kind of, you can see, you can tell she's desperate for someone to reassure her, so she really does kind of reach out and she's like, you know, kind of, just tell me I'm normal, tell me I'm sane, tell me I'm not going crazy. [asking for] any kind of relief, and just like frustration that she thinks that way" (Participant 3).

\section{Discussion}

The purpose of the present study was to explore caregivers' understanding and experiences of excessive reassurance seeking (ERS) within the context of OCD using a semi-structured interview. Although the results suggest how complex reassurance is for those who provide it, without exception participants reported experiencing a sense of frustration as a result of being frequently and repeatedly asked to provide reassurance. This is in line with the 'family accommodation' literature in which caregivers commonly report negative feelings, including frustration due to the sufferer's OCD symptoms (e.g., Ramos-Cerqueira, Torres, Torresan, Negreiros, \& Vitorino, 2008). When confronted with requests for reassurance, caregivers feel that they have to give in, although they also clearly understand that doing so I likely to have long-term counterproductive effects. Why then give it? The short answer to that question is that giving reassurance is experienced as effective, it provides some relief and can be helpful 'on the day' both for the sufferer and the caregiver. Where it is believed that giving reassurance makes it possible for both individuals to 'move on' as opposed to spending hours in torment, most people would understandably give reassurance. Equally importantly, the caregivers in this study simply do not know what else to do or offer - in the context of the belief that giving reassurance will make the OCD worse. Thus, it seems that they are 'stuck' and their goals are not being met (e.g. reassurance seeking does not stop, the OCD problem is 
maintained and they are essentially doing something they do not want to do). Consequently they feel frustrated with the situation they are in. Our findings are consistent with those from others, which show that caregivers of OCD patients are typically affected by their condition in a negative way. Some studies have shown that caregivers of OCD patients feel burdened and are more likely to experience psychological distress and have a lower quality of life (Grover \& Dutt, 2011; Ramos-Cerqueira et al., 2008; Vikas, Avasthi, \& Sharan, 2011). As pointed out elsewhere (e.g. Perlick et al., 2010) these factors may impact on patients' symptoms and create obstacles to recovery (Amir et al., 2000) - thereby highlighting the need for clinicians to consider involving caregivers more frequently in their treatments and developing interventions specifically aimed at family members of OCD patients. Some participants in the present study described having tried ways of substituting reassurance with something else without any effect, while others talked about being too afraid, of the consequences of withholding reassurance, to even try. Another justification for giving reassurance (apart from the shared relief it offers), is that providing reassurance can be seen as communicating love, care and concern for the person suffering from OCD where withholding it can suggest the opposite. Caregivers reported other concerns about withholding reassurance, such as causing more emotional suffering, triggering a negative behavioral response in the form of anger, aggression, threats, or in some severe cases a refusal to eat or drink. This highlights the complexity involved (and perhaps inappropriateness) in telling caregivers to withhold reassurance in the absence of any alternatives (e.g. access to treatment). This study also provided insight from the perspective of caregivers into what takes place during the course of the provision of reassurance. Some participants described how they were required to give reassurance in the 'correct way' where careful attention was paid to their answers and body language. This included criticizing their answers, analysing the tone of their voice, and scrutinizing their faces. Failing these 'standards' typically triggered more persistent reassurance seeking and an increase in negative feelings. These factors are very similar to the 
counterproductive 'stop criteria' which Salkovskis (1999) and Wahl, Salkovskis, and Cotter (2008) suggested that some obsessional patients follow in response to the perception of threat and responsibility for harm. Applying this framework would suggest that reassurance seeking stops when various subjective criteria, such as internal states of feelings or moods, and objective criteria (external observations), have been fulfilled. For example, the person giving the reassurance must look in a certain way (objective), their tone of voice must sound 'confident' (objective) and the sufferer has to feel completely rid of anxiety (subjective). An implication of this is that the behavior becomes more persistent and prolonged because fulfilling all the 'necessary' criteria is almost (if not entirely) impossible. To the authors knowledge no other studies have exclusively focused on caregiver's understanding and experiences of reassurance seeking. However, the present study is a follow-up study from Kobori et al. (2012) protocol, where individuals suffering from OCD were asked to reflect on their experiences of reassurance, using a similar interview structure. Thus, findings from these two studies can be matched to examine similarities and differences between caregivers' and OCD sufferers' understanding and experiences of excessive reassurance seeking. Consistent with the present findings (and also Parrish \& Radomsky, 2010), Kobori et al. (2012) found that the function of reassurance for OCD patients is to deal with the perception of threat. The authors concluded that reassurance seeking is a form of obsessional checking, motivated to remove all elements of uncertainty and dispersing the responsibility of harm onto others. According to the authors this was reflected in terms of how the OCD patients described striving to achieve a feeling of complete certainty, perfection or being right when seeking reassurance. In comparison with the current findings, intolerance of uncertainty was endorsed and manifest in the present study in terms of how caregivers defined reassurance, as 'saying things will be ok, clarifying or confirming' and in terms of how some participants were required to provide reassurance in the 'correct' way. In comparison to Kobori and colleagues' (2012) findings, diminishing responsibility for harm was slightly less frequently 
endorsed as a function of reassurance seeking. It featured in some of the interviews but was not considered to be a subtheme. However, it is argued here that this is to be expected since the manner in which the 'dispersion of responsibility' is expressed is mostly hidden from caregivers. In other words, even if many OCD patients' intention is to diminish responsibility for harm when seeking reassurance, they are unlikely to directly express this in comparison with for example the need to feel less anxious. Another strand of research where qualitative methods were employed to examine ERS in OCD patients (Parrish \& Radomsky, 2010) also reported that diminishing responsibility for harm was rarely endorsed as a principal component for reassurance seeking. Similar reasons were used to explain this absence. We must also take into account the possibility that the dispersion of responsibility is not a defining feature of reassurance seeking within the context of OCD. Further research is clearly needed to answer this question. Equally, this may be a result of the current data collection method (i.e. participants were not directly asked about the dispersion of responsibility). Further comparison with Kobori et al. (2012) shows that caregivers and OCD patients are fully aware of the short-lived effects of reassurance and realize that it is counterproductive. It would appear to follow that it should not be sought and, equally, not provided. Interestingly, this notion does not prevent reassurance seeking or the provision of it. Both studies indicated that the multiple criteria may need to be met for reassurance to have its desired impact; e.g. absence or presence of certain facial expressions, frequency of the provision of reassurance, the correct tone of voice. With regards to interpersonal problems, caregivers said that ERS put strain on them and impacted negatively on their quality of life. OCD patients are aware of this (Kobori et al., 2012) and as a result may try to terminate the behavior (Parrish \& Radomsky, 2010) or employ other strategies, such as by seeking reassurance in hidden ways or becoming very careful in choosing the 'right' people at the 'correct' time to minimise confrontations (Kobori et al., 2012). Most of the time these attempts fail - the obsessional belief overrides everything and reassurance is sought. 


\section{Study Limitations}

An important limitation of this study relates to the generalizability of the findings. The sample size was relatively small and consisted mostly of women. Also, the recruitment procedure was restricted to two specialist anxiety clinics and self-help organisations. There may of course be discrepancies between how caregivers describe reassurance and what actually takes place in real life. These issues need to be taken into account when the results are considered as they might mean that the themes that were extracted may not fit to the broader community of caregivers of OCD patients.

\section{Conclusions}

These findings have implications for treating reassurance seeking within the context of OCD and may also generalise to other emotional problems, such as health anxiety, where ERS frequently forms part of the presenting problem. A key finding is that the caregivers in this study feel unable to cope without giving reassurance - they consider that they have few alternatives. Understandably this causes upset and frustration because they feel stuck; caregivers usually know that reassurance is only 'helpful on the day' and simultaneously they are only feeding the OCD. The results clearly highlight that it is important that therapists work to understand the interpersonal context in which reassurance is sought and provided. It is suggested here that therapists should conceptualise reassurance seeking as a form of safety-seeking behavior, best understood as a verbal compulsive checking behavior. Asking family members to withhold any reassurance (or ignore the request) may not be a useful strategy. A more subtle approach may be more appropriate, particularly in severe anxiety problems and particularly in relationships consumed by reassurance. Ideally, good treatment should involve helping the sufferer stop seeking reassurance in the same way as they are helped to stop washing and checking in CBT. It is suggested that we need to evaluate the impact of helping patients make the transition from seeking reassurance to seeking support for example presented within a 'theory A versus theory B' framework (Salkovskis, 1999). Our 
group has begun single case experimental study with good results and further research is under way.

\section{References}

Abramowitz, J. S., Baucom, D. H., Wheaton, M. G., Boeding, S., Fabricant, L. E., Paprocki, C., \& Fischer, M. S. (2013). Enhancing Exposure and Response Prevention for OCD: A CoupleBased Approach. Behavior Modification, 37(2), 189-210.

Abramowitz, J. S., \& Braddock, A. E. (2008). Psychological treatment of health anxiety \& hypochondriasis: A biopsychosocial approach: Cambridge MA. Hogrefe and Huber.

Albert, U., Bogetto, F., Maina, G., Saracco, P., Brunatto, C., \& Mataix-Cols, D. (2010). Family accommodation in obsessive-compulsive disorder: Relation to symptom dimensions, clinical and family characteristics. Psychiatry Research, 179(2), 204-211.

Amir, N., Freshman, M., \& Foa, E. B. (2000). Family Distress and Involvement in Relatives of Obsessive-Compulsive Disorder Patients. Journal of Anxiety Disorders, 14(3), 209-217.

Boeding, S. E., Paprocki, C. M., Baucom, D. H., Abramowitz, J. S., Wheaton, M. G., Fabricant, L. E., \& Fischer, M. S. (2013). Let me check that for you: Symptom accommodation in romantic partners of adults with Obsessive-Compulsive Disorder. Behaviour Research and Therapy, 51(6), 316-322.

Bolton, D., Williams, T., Perrin, S., Atkinson, L., Gallop, C., Waite, P., \& Salkovskis, P. (2011). Randomized controlled trial of full and brief cognitive-behaviour therapy and wait-list for paediatric obsessive-compulsive disorder. Journal of Child Psychology and Psychiatry, 52(12), 1269-1278.

Braun, V., \& Clarke, V. (2006). Using thematic analysis in psychology. Qualitative Research in Psychology, 3(2), 77-101. 
Calvocoressi, L., Lewis, B., Harris, M., Trufan, S. J., Goodman, W. K., McDougle, C. J., \& Price, L. H. (1995). Family accommodation in obsessive-compulsive disorder. American Journal of Psychiatry, 152(3), 441-443.

Ferrão, Y. A., Shavitt, R. G., Bedin, N. R., de Mathis, M. E., Carlos, A., Fontenelle, L. F., . . . Miguel, E. C. (2006). Clinical features associated to refractory obsessive-compulsive disorder. Journal of Affective Disorders, 94(1-3), 199-209.

Furer, P., Walker, J., \& Freeston, M. (2001). Approach to integrated cognitive-behavior therapy for intense illness worries. In J. G. A. Gordon, T. Steven, \& J. C. Brian (Eds.), Health anxiety: clinical and research perspective on hypchondirasis and related conditions (pp. 161-192). New York: John Wiley \& Sons.

Grover, S., \& Dutt, A. (2011). Perceived burden and quality of life of caregivers in obsessivecompulsive disorder. Psychiatry and Clinical Neurosciences, 65(5), 416-422.

Kobori, O., \& Salkovskis, P. M. (2009). "No shit?" An experiment on the effects of reassurance in contamination OCD. Symposium "New findings extending the cognitive behavioural understanding of $O C D^{\prime \prime}$. . Paper presented at the European Association for Behavioural Cognitive Therapy, Dubrovnik, Croatia.

Kobori, O., \& Salkovskis, P. M. (2013). Patterns of reassurance seeking and reassurance-related behaviours in OCD and anxiety disorders. Behav Cogn Psychother, 41(1), 1-23.

Kobori, O., Salkovskis, P. M., Read, J., Lounes, N., \& Wong, V. (2012). A qualitative study of the investigation of reassurance seeking in obsessive-compulsive disorder. Journal of Obsessive-Compulsive and Related Disorders, 1(1), 25-32.

Kobori, O., Sawamiya, Y., Iyo, M., \& Shimizu, E. (2014). A Comparison of Manifestations and Impact of Reassurance Seeking among Japanese Individuals with OCD and Depression. Behavioural and Cognitive Psychotherapy, FirstView, 1-12. 
Lebowitz, E. R., Omer, H., \& Leckman, J. F. (2011). Coercive and disruptive behaviors in pediatric obsessive-compulsive disorder. Depression and Anxiety, 28(10), 899-905.

Lewin, A. B., Park, J. M., Jones, A. M., Crawford, E. A., DeNadai, A. S., Menzel, J., . . . Storch, E. A. (2014). Family-based exposure and response prevention therapy for preschool-aged children with obsessive-compulsive disorder: a pilot randomized controlled trial. Behaviour Research and Therapy, 56, 30-38.

Mehta, M. (1990). A comparative study of family-based and patient-based behavioural management in obsessive-compulsive disorder. The British Journal of Psychiatry, 157(1), 133-135.

Parrish, C. L., \& Radomsky, A. S. (2006). An experimental investigation of responsibility and reassurance: Relationships with compulsive checking. International Journal of Behavioral Consultation and Therapy, 2(2), 174-191.

Parrish, C. L., \& Radomsky, A. S. (2010). Why do people seek reassurance and check repeatedly? An investigation of factors involved in compulsive behavior in OCD and depression. Journal of Anxiety Disorders, 24(2), 211-222.

Parrish, C. L., \& Radomsky, A. S. (2011). An Experimental Investigation of Factors Involved in Excessive Reassurance Seeking: The Effects of Perceived Threat, Responsibility and Ambiguity on Compulsive Urges and Anxiety. Journal of Experimental Psychopathology, 2(1), 44-62.

Peris, T. S., Bergman, R. L., Langley, A., Chang, S., McCracken, J. T., \& Piacentini, J. (2008). Correlates of Accommodation of Pediatric Obsessive-Compulsive Disorder: Parent, Child, and Family Characteristics. Journal of the American Academy of Child \& Adolescent Psychiatry, 47(10), 1173-1181. 
Perlick, D. A., Miklowitz, D. J., Lopez, N., Chou, J., Kalvin, C., Adzhiashvili, V., \& Aronson, A. (2010). Family - focused treatment for caregivers of patients with bipolar disorder. Bipolar disorders, 12(6), 627-637.

Rachman, S. (2002). A cognitive theory of compulsive checking. Behaviour Research and Therapy, 40(6), 625-639.

Ramos-Cerqueira, A. T. d. A., Torres, A. R., Torresan, R. C., Negreiros, A. P. M., \& Vitorino, C. N. (2008). Emotional burden in caregivers of patients with obsessive-compulsive disorder. Depression and Anxiety, 25(12), 1020-1027.

Renshaw, K. D., Caska, C. M., Rodrigues, C. S., \& Blais, R. K. (2012). The Role of Family and Social Relationships in OCD and Spectrum Condition. In G. Steketee (Ed.), The Oxford Handbook of Obsessive Compulsive and Spectrum Disorders (pp. 168-188). Oxford: Oxford University Press.

Renshaw, K. D., Steketee, G., \& Chambless, D. L. (2005). Involving Family Members in the Treatment of OCD. Cognitive Behaviour Therapy, 34(3), 164-175.

Salkovskis, P. M. (1991). The Importance of Behavior in the Maintenance of Anxiety and Panic a Cognitive Account. Behavioural Psychotherapy, 19(1), 6-19.

Salkovskis, P. M. (1996). The Cognitive Approach to Anxiety: Threat Beliefs, Safety-Seeking Behavior, and the Special Case of Health Anxiety and Obsessions. In P. M. Salkovskis (Ed.), Frontiers of cognitive therapy (pp. 48-74). New York: The Guilford Press.

Salkovskis, P. M. (1999). Understanding and treating obsessive-compulsive disorder. Behaviour Research and Therapy, 37(Suppl 1), S29-52.

Salkovskis, P. M., \& Kobori, O. (2015). Reassuringly Calm? Self-reported patterns of responses to reassurance seeking in Obsessive Compulsive Disorder. Journal of Behavior Therapy and Experimental Psychiatry. 
Shafran, R., Ralph, J., \& Tallis, F. (1995). Obsessive-compulsive symptoms and the family. Bulletin of the Menninger Clinic, 59(4), 472-479.

Steketee, G., \& Van Noppen, B. (2003). Family Approaches to Treatment for Obsessive Compulsive Disorder. Journal of Family Psychotherapy, 14(4), 55-71.

Stewart, S. E., Beresin, C., Haddah, S., Stack, D., Farna, J., \& Jenike, M. (2008). Predictors of family accommodation in obsessive-compulsive disorder. Annals of Clinical Psychiatry, 20(2), 65-70.

Storch, E. A., Geffken, G. R., Merlo, L. J., Jacob, M. L., Murphy, T. K., Goodman, W. K., ... Grabill, K. (2007). Family Accommodation in Pediatric Obsessive-Compulsive Disorder. Journal of Clinical Child \& Adolescent Psychology, 36(2), 207-216.

Storch, E. A., Larson, M. J., Muroff, J., Caporino, N., Geller, D., Reid, J. M., . . Murphy, T. K. (2010). Predictors of functional impairment in pediatric obsessive-compulsive disorder. Journal of Anxiety Disorders, 24(2), 275-283.

Taylor, S., Asmundson, G. J., \& Coons, M. J. (2005). Current Directions in the Treatment of Hypochondriasis. Journal of Cognitive Psychotherapy, 19(3), 285-304.

Vikas, A., Avasthi, A., \& Sharan, P. (2011). Psychosocial Impact of Obsessive-Compulsive Disorder on Patients and Their Caregivers: a Comparative Study With Depressive Disorder. International Journal of Social Psychiatry, 57(1), 45-56.

Wahl, K., Salkovskis, P. M., \& Cotter, I. (2008). 'I wash until it feels right' the phenomenology of stopping criteria in obsessive-compulsive washing. Journal of Anxiety Disorders, 22(2), 143-161. 